Article

\title{
Optimal Pricing, Advertising, Production, Inventory and Investing Policies in a Multi-Stage Sustainable Supply Chain
}

\author{
Jia-Liang Pan ${ }^{1}$, Chui-Yu Chiu ${ }^{2}$, Kun-Shan $W u^{3, *(\mathbb{D}, \text { Chih-Te Yang }}{ }^{4, * \mathbb{C}}$ and Yen-Wen Wang ${ }^{5}$ \\ 1 College of Management, National Taipei University of Technology, Taipei 10608, Taiwan; \\ t108749403@ntut.org.tw \\ 2 Department of Industrial Engineering and Management, National Taipei University of Technology, \\ Taipei 10608, Taiwan; cychiu@ntut.edu.tw \\ 3 Department of Business Administration, Tamkang University, Taipei 251301, Taiwan \\ 4 Department of International Business, Chien Hsin University of Science and Technology, \\ Taoyuan 32097, Taiwan \\ 5 Department of Industrial Management, Chien Hsin University of Science and Technology, \\ Taoyuan 32097, Taiwan; ywwang@uch.edu.tw \\ * Correspondence: kunshan@mail.tku.edu.tw (K.-S.W.); ctyang@uch.edu.tw (C.-T.Y.)
}

Citation: Pan, J.-L.; Chiu, C.-Y.; Wu, K.-S.; Yang, C.-T.; Wang, Y.-W. Optimal Pricing, Advertising, Production, Inventory and Investing Policies in a Multi-Stage Sustainable Supply Chain. Energies 2021, 14, 7544. https://doi.org/10.3390/en14227544

Academic Editors: Donato Morea and Beata Zofia Filipiak

Received: 8 October 2021

Accepted: 7 November 2021

Published: 11 November 2021

Publisher's Note: MDPI stays neutral with regard to jurisdictional claims in published maps and institutional affiliations.

Copyright: (c) 2021 by the authors. Licensee MDPI, Basel, Switzerland. This article is an open access article distributed under the terms and conditions of the Creative Commons Attribution (CC BY) license (https:/ / creativecommons.org/licenses/by/ $4.0 /)$.

\begin{abstract}
In this paper, the study of a sustainable production-inventory model with price and advertisement dependent on demand considering carbon emission reduction technology is investigated. The aim of this paper is to determine the optimal appropriate pricing, advertising, production, inventory, and capital investment decisions under various carbon emission policies to maximize the joint total profit of a multi-stage supply chain system. Various theoretical results and an algorithm are provided to verify and obtain the optimal solution of the problem. Further, the model is verified by numerical examples, and the robustness check of parameter variation is also analyzed. Finally, some management implications for decision makers are drawn from numerical examples. In summary, this study puts forward more realistic modeling hypothesis, which is beneficial to the academic research, and the research results can provide relevant decision makers with a model for managing a sustainable supply chain.
\end{abstract}

Keywords: carbon emissions; inventory; sustainable supply chain management; advertisement; pricing

\section{Introduction}

With the negative impact of climate change on the environment, society, and even companies, sustainable development has become one of the most important issues that companies pay attention to. One of the major climate change factors and environmental threats is carbon emissions. The various activities of enterprises, such as production, inventory, sales, and transportation consume resources and energy, leading to carbon emissions, waste, and pollution. As environmental pollution becomes more and more serious, carbon emissions must be regulated and restricted. In order to reduce carbon emissions, many countries, especially developed ones, are beginning to discuss the threat and set emission standards.

From the Kyoto Protocol in 1997 to the Paris Agreement in 2015 and the initiative to promote Net Zero Emissions in recent years, the regulation of carbon emissions is not only the trend of the future but will also be actively implemented. For example, carbon capand-trade, carbon tax, carbon offset and other mechanisms have been based on to reducing the increasing amount of carbon emissions. In the face of future pressure that may come from the government, customers and other stakeholders, companies must pay attention to the impact of the entire product life cycle on the environment and ecology, take actions to reduce the impact of their operations on the environment and society, and adapt to growing environmental awareness [1]. In the past 10 years, many scholars have conducted extensive theoretical and empirical studies on the subject of linking sustainability and supply chain 
management (SCM) concepts and published the research in various influential academic journals (for example, Gong et al. [2], Zimon et al. [3], Baghizadeh et al. [4]) using two terms in the literature: green supply chain management (GSCM) and sustainable supply chain management (SSCM). Although the definitions of SSCM and GSCM are slightly different [5], they both can be described as managing organizational supply chains to maximize profitability and reduce negative environmental impacts [6]. Some scholars have found that companies can significantly reduce carbon emissions without significantly increasing cost by weakening inventory management or supply chain management [7].

Further, in 2015, the United Nations announced the Sustainable Development Goals (SDGs), including 17 goals such as poverty eradication, climate change mitigation, and promotion of gender equality, guiding global efforts to achieve sustainability. If SSCM and GSCM practices can be integrated into the SDGs, it will enable entrepreneurs to transition into more stable, efficient, and ethical supply chains [8]. However, though green products have become more and more popular, they require a huge amount of investment. This may reduce the willingness and ability of enterprises to invest in green products. Moreover, so-called green products cannot be achieved by individual companies. A company with better environmental performance is likely to be dragged down by suppliers with weaker environmental performance. Therefore, environmental thinking should be integrated into the entire supply chain management process, including product design, material sourcing and selection, manufacturing process, delivery of final products to consumers, and end-of-life management of the product after its useful life [9]. Among them, discussing how to effectively integrate the upstream to downstream of the supply chain, so as to effectively implement corporate green activities in all links of the industry chain, is a key factor in the promotion of green products. Therefore, from the supply chain system integration perspective, if supply chain members can jointly invest in carbon reduction technology, share the cost saving and increased benefits brought by carbon reduction, it will be conducive to the development of green products. That is, investment in the development of green products can not only effectively reduce the amount of carbon emissions, but also contribute to help save energy (such as electricity).

In addition, awareness of promotional schemes can be spread in an effective way to customers through proper advertisement of the product. Advertisement can be executed in different ways such as distribution of leaflets, setting banners, through communication means such as television, radio, newspaper, social media, and so on. Although advertising can effectively increase market demand, it also requires investment. How to coordinate with the price of the product to determine the optimal advertising fee and selling price is an important and relevant issue that companies should pay attention to. Based on the current consumer awareness of environmental protection, strengthening green advertising will more effectively increase demand.

According to the aforementioned argument, the article develops a sustainable productioninventory model with price and advertisement dependent demand based on consideration of the carbon emission reduction technology. The model considers two usual carbon emissions policies: carbon cap-and-trade and carbon taxes. The primary objective is to simultaneously determine optimal pricing, advertising, production, replenishment, and investment decisions under the carbon taxes and carbon cap-and-trade policies. Various theoretical results and an algorithm are provided to verify and obtain the optimal solution of the problem. Further, the model is verified by numerical examples, and the robustness check of parameter variation is also analyzed. Finally, some management implications for decision makers are drawn from numerical examples.

The remainder of this article is structured as follows: Section 2 discusses the review of earlier studies and compares the differences between this study and previous research to highlight research contributions; Section 3 displays the notations and assumptions in the proposed model; Section 4 presents the research models and empirical results; Section 5 discusses the effects of parameter changes, and finally in Section 6, conclusions, suggestions, and further works are presented. 


\section{Literature Overview}

\subsection{Sustainable Production-Inventory Models}

The amount of research on product-inventory models considering carbon emission issues has increased after the authors developed an economic order quantity (EOQ) or economic production quantity (EPQ) with sustainability considerations which can be divided into two categories, namely, carbon-related constraints (for example carbon cap) and carbon price (for example carbon tax) [1,10-14]. For example, the study of [15] established a deterministic optimization model that incorporates carbon emissions into a multistage production-inventory model subject to lead time constraints, and with carbon emissions tax and carbon emissions cap. Datta [16] addressed the influence of green investment on a production-inventory system under carbon tax where the demand is dependent on the selling price and the production rate is variable. Gautam and Khanna [17] developed an imperfect production-inventory model with setup cost reduction and carbon emission from the individual and integrated point of view. Shen et al. [18] investigated a production-inventory model for deteriorating items under a carbon tax policy where the preservation technology investment is considered. Asghar et al. [19] studied stochastic production inventory strategy with stochastic production capacities and energy consumption. Zavanella et al. [20] also developed a joint economic lot size model from the single-vendor single-buyer supply chain perspective by considering energy as a key factor. Further, Chen and Bidanda [21] addressed a new production-inventory problem of multiple factories based on resource recycling and emission reduction.

Lu et al. [22] explored the production-inventory model under the carbon offset and carbon cap-and-trade policy, according to the Stackelberg game theory. Pan et al. [23] explored the production-inventory model with the carbon tax and carbon cap-and-trade policy in which members of an integrated supply chain agreed to co-invest capital to reduce carbon emissions. More recently, Sepehri and Gholamian [24] also elaborated a sustainable production-inventory model for poor quality deteriorated items using preservation technology, carbon reduction technology, and quality improvement simultaneously.

\subsection{Inventory Model with Price and Advertisement Effect}

There are several articles on inventory models in which product demand is sensitive to advertisement effect in the inventory literatures. Das et al. [25] proposed an integrated inventory model with permissible delay in payment where the demand rate depends on the advertisement and selling price of the item. Geetha and Udayakumar [26] took the price and advertising dependence demand function to develop an inventory model with partial backlogging. Soni and Chauhan [27] explored the pricing and replenishment decisions for deteriorated items whose price and promotional efforts depend on demand and preservation technology investment. Soni and Suthar [28] investigated the effect of pricing and promotional effort in an inventory model for non-instantaneous deteriorating items. Mashud et al. [29] further considered a non-instantaneous deteriorating inventory model with price- and advertisement-dependent demand, trade credit, partial backlogging, and preservation technology investment, simultaneously. Khan et al. [30] formulated two inventory models (with/without shortages) for deteriorating items with advanced payment, linearly time-dependent holding cost and demand dependent on advertisement and selling price. More recently, San-José et al. [31] studied a new lot size inventory problem for products whose demand pattern is dependent on price, advertising frequency, and time.

\subsection{Research Gap and Contribution}

As previously noted, we reveal the main differences between this study and the above-mentioned previous relevant studies in Table 1. It is found that from Table 1, although previous studies about inventory models with carbon emission reduction policies or with price- and advertisement-dependent demand have been discussed, few have taken the co-investment agreements of carbon emission reduction technology into account and 
considered the inventory problem of a multi-stage supply chain including materials and finished products at the same time. Further, a continuous-time optimal control model is often used to construct the production-inventory model because it provides good production and replenishment policies in many settings and applications, such as routing, manufacturing, supply chain, and transportation systems [32]. Therefore, the main contribution of this study is that (1) the multistage issues of raw materials and finished products which is different from other previous research; (2) the co-investment in carbon emission reduction technology between the vendor and the buyer is considered in a continuous-time framework; and (3) investment, pricing, and advertising effectiveness are simultaneously taken into account in the proposed model.

Table 1. Comparison of the main characteristics of this study and previous research.

\begin{tabular}{|c|c|c|c|c|c|c|}
\hline References & Model & $\begin{array}{c}\text { Carbon Emission } \\
\text { Effect }\end{array}$ & Multistage & $\begin{array}{c}\text { Carbon } \\
\text { Emission } \\
\text { Reduction } \\
\text { Technology }\end{array}$ & $\begin{array}{l}\text { Pricing } \\
\text { Strategy }\end{array}$ & $\begin{array}{c}\text { Advertising } \\
\text { Effect }\end{array}$ \\
\hline$[1,12]$ & EOQ & $\begin{array}{l}\text { Carbon cost } \\
\text { (1) Carbon cap }\end{array}$ & & & & \\
\hline$[7,11]$ & EOQ & $\begin{array}{l}\text { (2) Carbon tax } \\
\text { (3) Carbon } \\
\text { cap-and-trade }\end{array}$ & & & & \\
\hline$[10]$ & EOQ & $\begin{array}{l}\text { (4) Carbon offsets } \\
\text { (1) Direct accounting } \\
\text { (2) Carbon cap } \\
\text { (3) Carbon tax } \\
\text { (4) Carbon } \\
\text { cap-and-trade } \\
\text { (5) Carbon offsets } \\
\text { (1) Carbon cap }\end{array}$ & & & & \\
\hline [13] & EOQ & $\begin{array}{l}\text { (2) Carbon tax } \\
\text { (3) Carbon } \\
\text { cap-and-trade }\end{array}$ & & V & & \\
\hline [14] & EPQ & Carbon cost & & & & \\
\hline [15] & Production-inventory & $\begin{array}{l}\text { (1) Carbon cap } \\
\text { (2) Carbon tax }\end{array}$ & & & & \\
\hline [16] & Production-inventory & Carbon tax & & $\mathrm{V}$ & & \\
\hline [17] & Production-inventory & Carbon cost & & & & \\
\hline [18] & Production-inventory & Carbon tax & & & & \\
\hline$[19,20]$ & Production-inventory & & & & & \\
\hline$[21]$ & Production-inventory & $\begin{array}{l}\text { Carbon cost } \\
\text { (1) Carbon }\end{array}$ & & $\mathrm{V}$ & & \\
\hline$[22,23]$ & Production-inventory & $\begin{array}{l}\text { cap-and-trade } \\
\text { (2) Carbon offsets }\end{array}$ & & $\mathrm{V}$ & & \\
\hline$[24]$ & Production-inventory & $\begin{array}{l}\text { Carbon } \\
\text { cap-and-trade }\end{array}$ & & V & V & \\
\hline [25] & Production-inventory & & & & $\mathrm{V}$ & $\mathrm{V}$ \\
\hline [26-31] & EOQ & & & & V & V \\
\hline [32] & EPQ & & & & $\mathrm{V}$ & \\
\hline This paper & Production-inventory & $\begin{array}{l}\text { (1) Carbon } \\
\text { cap-and-trade } \\
\text { (2) Carbon tax }\end{array}$ & $\mathbf{V}$ & $\mathbf{V}$ & $\mathbf{V}$ & $\mathbf{V}$ \\
\hline
\end{tabular}

\section{Notation and Assumptions}

The mathematical model for the inventory system studied here is based on the following notation (put at the end of the article) and assumptions.

(1) A single vendor, single buyer, and single commodity is involved in the proposed supply chain system. 
(2) In reality, the vendor's productivity of finished products is usually greater than the demand rate (i.e., $P>D(p, M)$ ) and finite.

(3) The supply chain members mutually agree that the buyer orders $Q$ units and allows the supplier to ship in $n$ times with $q(=Q / n)$ units where the delivery cost is paid by the buyer.

(4) The demand is affected by advertisement efforts and selling price of product. That is, the demand rate is $D(p, M)=(a-b p)(\alpha+\beta M)$, where $a$ is constant scale demand parameter, $b$ is price elasticity factor, $\alpha$ and $\beta$ denote advertisement effectiveness factors.

(5) The buyer's carbon emissions originate from ordering, holding inventory, shipping, advertising, and purchasing activities while the vendor's carbon emissions originate from purchasing the materials, setting, production, and holding of materials.

(6) Based on the study of $[22,23]$, the model assumes that carbon emissions can be decreased by investing in carbon-reduction technologies. The carbon emission reduction rate, $m(\xi)$, is the increasing function of carbon emission reduction, $\xi$, where $0<m(\xi)<1$. Further, the carbon emission reduction investment is shared by the buyer and vendor through an agreement where the capital investment ratios of buyer and vendor are $\rho$ and $1-\rho$, respectively.

(7) Whether it is the finished products and materials of the buyer or the vendor, shortages are not permitted.

\section{Mathematical Model Formulation and Solution}

This study investigates a production-inventory model with price- and advertisementdependent demand for collaborative investment under carbon tax and carbon cap-andtrade policies. Before the model is formed, let's briefly explain the production-inventory system included in a single buyer and a single vendor process as follows.

During an entire production cycle (cycle length is $T_{v}$ ), the buyer orders $Q$ units at the beginning and asks the supplier to divide into $n$ consignments. That is, the quantity shipped is $q=Q / n$ units per shipment. At the same time, the supplier also places an order from its material supplier and purchases $Q_{m}$ units of raw materials for processing and production after receiving the retailer's order. Once the first production quantity $q$ is reached (cycle length is $T_{p}$ ), the supplier commences shipping during production and ships to the buyer. After that, the vendor ships $q$ units every fixed period (the length of the period is $T_{b}$ ). Once the vendor produces the quantity that can satisfy the retailer's order (the length of the period is $T_{s}$ ), it ceases production and continues to make regular shipments.

Figure 1 displays the production-inventory system of the buyer and vendor in a complete production cycle. According to the notation and assumptions, we then calculate the total profits and carbon emissions of the buyer and vendor respectively, as shown below.

\subsection{Total Profit and Carbon Emissions for the Buyer}

As can be seen from Figure 1, during a replenishment cycle, the buyer's inventory level (finished product) changes based on market demand and deterioration. That is, the changes in inventory level can be represented by the following differential equation:

$$
\frac{d I(t)}{d t}+\theta_{g} I(t)=-D(p, M), 0 \leq t \leq T_{b}
$$

Considering that $I\left(T_{b}\right)=0$ then the solution of Equation (1) is given by

$$
I(t)=\frac{(a-b p)(\alpha+\beta M)}{\theta_{g}}\left[e^{\theta_{g}\left(T_{b}-t\right)}-1\right], 0 \leq t \leq T_{b}
$$




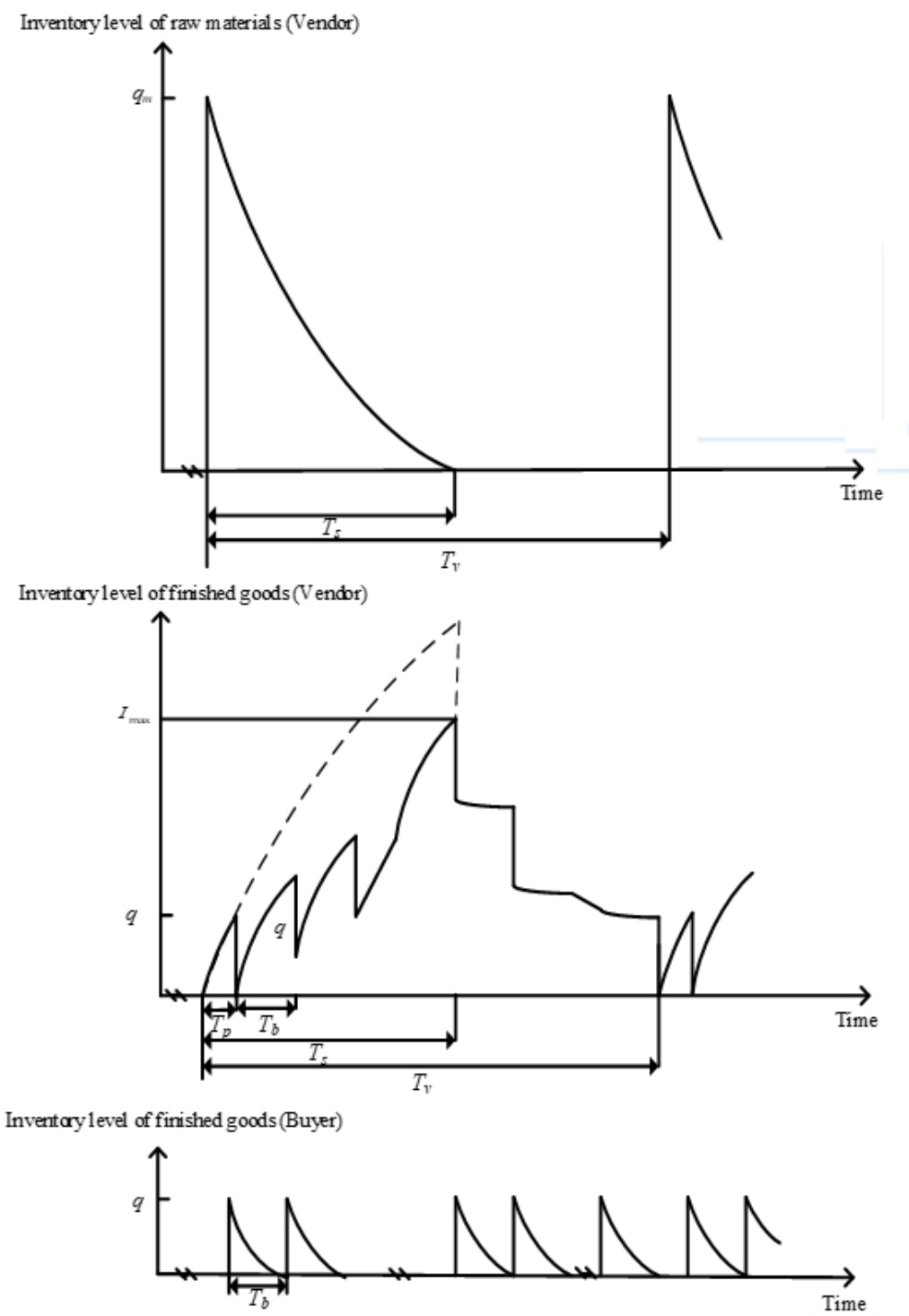

Figure 1. The production-inventory system for the buyer and vendor.

Substituting $t=0$ into Equation (2), and from the fact $q=I(0)$, it can get

$$
T_{b}=\frac{1}{\theta_{g}} \ln \left[\frac{\theta_{g} q+(a-b p)(\alpha+\beta M)}{(a-b p)(\alpha+\beta M)}\right]
$$

Next, we calculate the total profit in a replenishment cycle for the buyer, including sales revenue, ordering, shipping, procurement, promotional costs and carrying costs, as well as carbon emission reduction investments. These components of each replenishment cycle can be computed as shown below:

(a) The sale revenue of buyer is

$$
p D(p, M) T_{b}=\frac{p(a-b p)(\alpha+\beta M)}{\theta_{g}} \ln \left[\frac{\theta_{g} q+(a-b p)(\alpha+\beta M)}{(a-b p)(\alpha+\beta M)}\right]
$$

(b) The ordering cost of buyer is $A$.

(c) The purchase cost of buyer is $v q$.

(d) The transportation cost (includes fixed and variable costs) of buyer is $C_{T}+C_{t} q$.

(e) The promotional cost of buyer is $M q$. 
(f) The holding cost of buyer is

$$
h_{b} \int_{0}^{T_{b}} I(t) d t=h_{b}\left\{\frac{q}{\theta_{g}}-(a-b p)(\alpha+\beta M) \ln \left[\frac{\theta_{g} q+(a-b p)(\alpha+\beta M)}{(a-b p)(\alpha+\beta M)}\right]\right\}
$$

(g) The investment for carbon emission reduction of buyer is $\rho \xi$.

In summary, the total profit per unit of time of buyer (expressed by $T P_{b}(q, \xi, p, M)$ ) can be calculated as

$$
\begin{aligned}
T P_{b}(q, \xi, p, M) & =\left(p-\frac{h_{b}}{\theta_{g}}\right)(a-b p)(\alpha+\beta M)-\frac{1}{\theta_{g} \ln \left[\frac{\theta_{g} q+(a-b p)(\alpha+\beta M)}{(a-b p)(\alpha+\beta M)}\right]} \\
& \times\left[A+C_{T}+\left(C_{t}+v+\frac{h_{b}}{\theta_{g}}+M\right) q+\rho \xi\right]
\end{aligned}
$$

From Assumption 5, the carbon emissions originated with the buyer are related to the costs of ordering, shipping, purchasing, advertising, and carrying, which can be reduced by investing at the rate of carbon emissions reduction $m(\xi)$. Therefore, the carbon emissions per unit of time of buyer (represented by $E_{b}(q, \xi, p, M)$ ) can be computed as follows:

$$
\begin{aligned}
E_{b}(q, \xi, p, M) & =\frac{[1-m(\xi)]}{\theta_{g}}\left\{\hat{h}_{b} D+\left\{\ln \left[\frac{\theta_{g} q+(a-b p)(\alpha+\beta M)}{(a-b p)(\alpha+\beta M)}\right]\right\}^{-1}\right. \\
& \times\left[\hat{A}+\hat{C}_{T}+\left(\hat{C}_{t}+\hat{v}+\frac{\hat{h}_{b}}{\theta_{g}}+\hat{M}\right) q\right]
\end{aligned}
$$

\subsection{Total Profit and Carbon Emissions for the Vendor}

As previously mentioned, after receiving the retailer's order ( $Q$ units), each production stage begins with the purchase of materials. Among them, the material inventory level of vendors fluctuates due to the usage of production materials and the deterioration of materials during the time interval $\left[0, T_{S}\right]$. At the same time, once the vendor produces $q=Q / n$ units of finished goods, it delivers goods to the retailer for the first time and then ships the quantity of q every interval $T_{b}$ until all the quantity of order is delivered. The total shipments of a production cycle are $n$. Figure 1 depicts the inventory levels of materials and finished products over a full production cycle.

From Figure 1, within the time interval $\left[0, T_{S}\right]$, the inventory level of raw materials for vendor changes at time $t$, which is expressed by the following differential equation:

$$
d I_{M}(t) / d t+\theta_{m} I_{M}(t)=-r P, 0 \leq t \leq T_{s}
$$

By using the boundary condition $I_{M}\left(T_{S}\right)=0$, the vendor's inventory level of materials during the time interval $\left[0, T_{S}\right]$ can be obtained:

$$
I_{M}(t)=\frac{r P}{\theta_{m}}\left[e^{\theta_{m}\left(T_{s}-t\right)}-1\right], 0 \leq t \leq T_{s}
$$

From Equation (8), the total volume of raw materials per production cycle, $Q_{m}$, can be obtained as follows:

$$
Q_{M}=I_{M}(0)=\frac{r P}{\theta_{m}}\left(e^{\theta_{m} T_{s}}-1\right)
$$

Regarding the finished products, the inventory level varies with production and deterioration during the time interval $\left[0, T_{s}\right]$.

Based on Assumption 2, inventory of finished products gradually accumulates until the end of production, at which time the inventory level reaches a certain level $I_{\max }$. Figure 2 shows the accumulated inventory of vendors and buyers. From Figure 2, within 
the time interval $\left[0, T_{s}\right]$, the inventory level of finished products of vendors can be determined by the following equation:

$$
\frac{d I_{p}(t)}{d t}+\theta_{g} I_{p}(t)=P, 0 \leq t \leq T_{S}
$$

Inventory level of finished goods

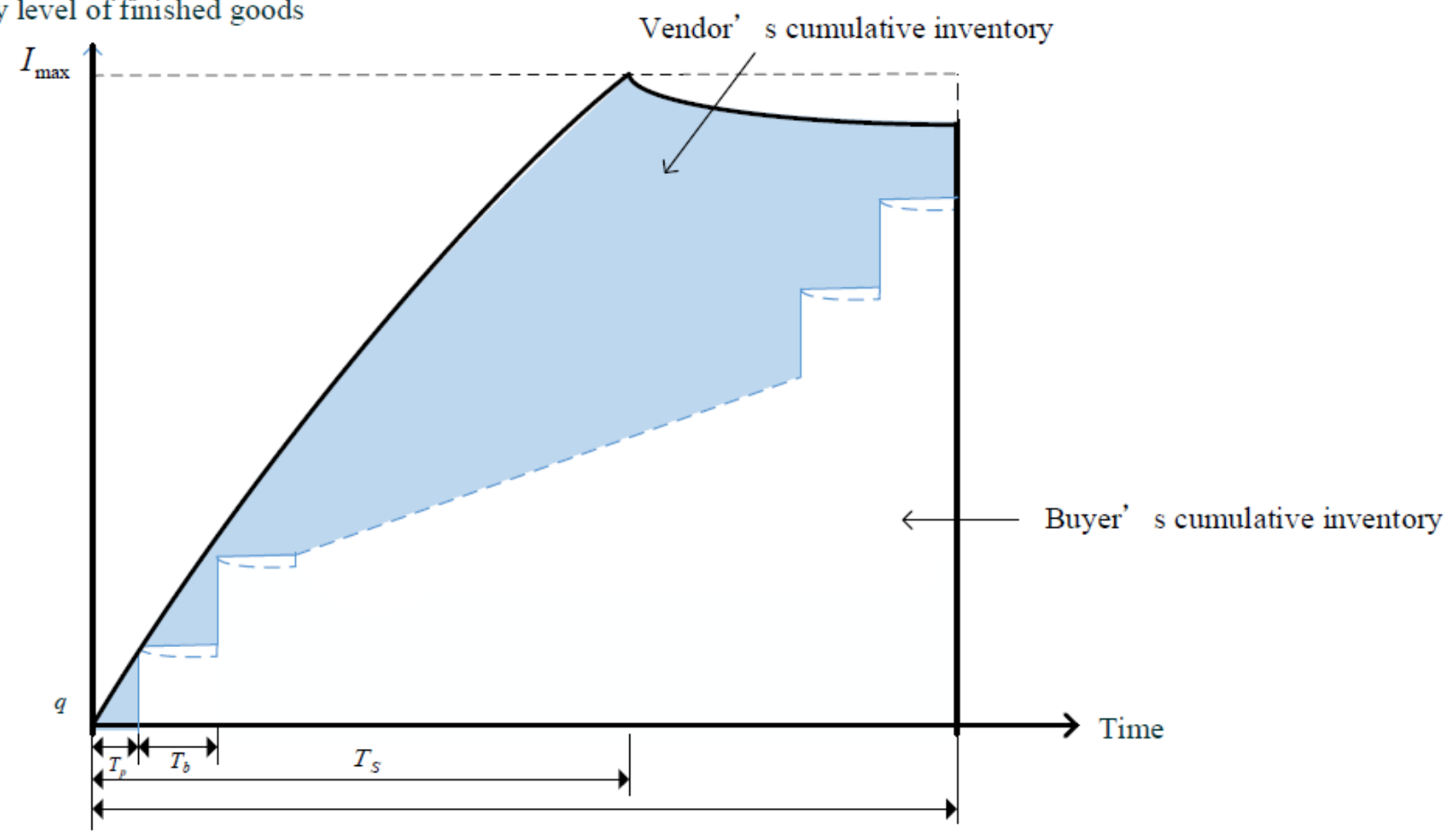

Figure 2. Cumulative inventory for the vendor and buyer.

Considering that $I_{p}(0)=0$ then the solution of Equation (10) is given by

$$
I_{p}(t)=\frac{P}{\theta_{g}}\left(1-e^{-\theta_{g} t}\right), 0 \leq t \leq T_{S}
$$

From Figure $2, I_{p}\left(T_{p}\right)=q$, which implies

$$
T_{p}=\frac{1}{\theta_{g}} \ln \left[\frac{P}{P-\theta_{g} q}\right]
$$

During the time interval $\left[T_{s}, T_{v}\right]$, the inventory level of finished products of vendors decreases due to its deterioration, which can be expressed as:

$$
\frac{d I_{d}(t)}{d t}+\theta_{g} I_{d}(t)=0, T_{s} \leq t \leq T_{v}
$$

Likewise, the inventory level of finished products of vendors during the time interval $\left[T_{s}, T_{v}\right]$ shown as Equation (13) can be found by $I_{d}\left(T_{v}\right)=n q$, which yields

$$
I_{d}(t)=n q e^{\theta_{g}\left(T_{v}-t\right)}, T_{s} \leq t \leq T_{v}
$$

From Equations (11), (14) and $I_{p}\left(T_{S}\right)=I_{d}\left(T_{s}\right)$, the length of $T_{s}$ can be expressed as

$$
T_{S}=\frac{1}{\theta_{g}} \ln \left[\frac{P+\theta_{g} n q e^{\theta T_{v}}}{P}\right]
$$


The total profit per production cycle of vendor is equal to sales revenue minus relevant costs included in the ordering cost for raw materials, setup cost, materials cost, production cost, holding costs, and investment for carbon emissions reduction. The above components are evaluated as follows:

(a) The vendor's sale revenue is $v Q=v n q$.

(b) The vendor's ordering cost for raw materials is $K$.

(c) The vendor's setup cost is $S$.

(d) The vendor's materials cost is

$$
c_{1} q_{M}=\frac{c_{1} r P}{\theta_{m}}\left(e^{\theta_{m} T_{s}}-1\right)
$$

(e) The vendor's production cost is

$$
c P T_{S}=\frac{c P}{\theta_{g}} \ln \left[\frac{P+\theta_{g} n q e^{\theta_{g} T_{v}}}{P}\right]
$$

(f) Holding cost:

There are two parts for the vendor's holding cost. One is the holding cost of raw materials, and the other is the holding cost of finished goods. The holding cost of raw materials is

$$
h_{m} \int_{0}^{T_{s}} I_{M}(t) d t=\frac{h_{m} r P}{\theta_{m}^{2}}\left(e^{\theta_{m} T_{s}}-\theta_{m} T_{s}-1\right)
$$

As for the holding cost of finished goods, the total inventory of finished goods of the vendor is equal to its accumulated inventory minus the accumulated inventory of the buyer (Figure 2), is given by $\int_{0}^{T_{s}} I_{p}(t) d t+\int_{T_{s}}^{T_{v}} I_{d}(t) d t q T_{b}[(1+2+\ldots+(n-1)]$. That is, the carrying cost of finished goods for vendor in a production cycle is

$$
\begin{aligned}
& h_{v}\left\{\int_{0}^{T_{s}} I_{p}(t) d t+\int_{T_{s}}^{T_{v}} I_{d}(t) d t-q T_{b}[(1+2+\ldots+(n-1)]\}\right. \\
= & h_{v}\left[\int_{0}^{T_{s}} \frac{P}{\theta_{g}}\left(1-e^{-\theta_{g} t}\right) d t+\int_{T_{s}}^{T_{v}} n q e^{\theta_{g}\left(T_{v}-t\right)} d t-\frac{n(n-1) q T_{b}}{2}\right] \\
= & h_{v}\left\{\frac{P}{\theta_{g}^{2}} \ln \left[\frac{P+\theta_{g} n q e^{\theta_{g} T_{v}}}{P}\right]-\frac{n q}{\theta_{g}}-\frac{n(n-1) q}{2 \theta_{g}} \ln \left[\frac{\theta_{g} q+(a-b p)(\alpha+\beta M)}{(a-b p)(\alpha+\beta M)}\right]\right\}
\end{aligned}
$$

(g) The carbon emission reduction technology investment shared by suppliers is $(1-\rho)$.

In summary, the total profit per unit of time of the vendor (represented by $\left.T P_{v}\left(T_{v}, q, n, \xi, p, M\right)\right)$ can be computed as

$$
\begin{gathered}
T P_{v}\left(T_{v}, q, n, \xi, p, M\right)=\frac{1}{T_{v}}\left\{v n q-S-K-\frac{c P}{\theta_{g}} \ln \left[\frac{P+\theta_{g} n q e^{\theta T_{v}}}{P}\right]-\frac{c_{1} r P}{\theta_{m}}\left(e^{\theta_{m} T_{s}}-1\right)\right. \\
-\frac{h_{m} r P}{\theta_{m}^{2}}\left(e^{\theta_{m} T_{s}}-\theta_{m} T_{S}-1\right)-h_{v}\left\{\frac{P}{\theta_{g}^{2}} \ln \left[\frac{P+\theta_{g} n q e^{\theta T_{v}}}{P}\right]-\frac{n q}{\theta_{g}}\right. \\
\left.\left.-\frac{n(n-1) q}{2 \theta_{g}} \ln \left[\frac{\theta_{g} q+(a-b p)(\alpha+\beta M)}{(a-b p)(\alpha+\beta M)}\right]-(1-\rho) \xi\right\}\right\}
\end{gathered}
$$

Similarly, from Assumption 5, the carbon emissions per unit of time of the vendor (represented by $E_{v}\left(T_{v}, q, n, \xi, p, M\right)$ ) is

$$
\begin{gathered}
E_{v}\left(T_{v}, q, n, \xi, p, M\right)=\frac{[1-m(\xi)]}{T_{v}}\left\{\hat{S}+\hat{K}+\frac{\hat{c} P}{\theta_{g}} \ln \left[\frac{P+\theta_{g} n q e^{\theta_{g} T_{v}}}{P}\right]+\frac{\hat{c}_{1} r P}{\theta_{m}}\left(e^{\theta_{m} T_{s}}-1\right)\right. \\
+\frac{\hat{h}_{m} r P}{\theta_{m}^{2}}\left(e^{\theta_{m} T_{s}}-\theta_{m} T_{S}-1\right)+\hat{h}_{v}\left\{\frac{P}{\theta_{g}^{2}} \ln \left[\frac{P+\theta_{g} n q e^{\theta_{g} T_{v}}}{P}\right]\right. \\
\left.\left.-\frac{n q}{\theta_{g}}-\frac{n(n-1) q}{2 \theta_{g}} \ln \left[\frac{\theta_{g} q+(a-b p)(\alpha+\beta M)}{(a-b p)(\alpha+\beta M)}\right]\right\}\right\}
\end{gathered}
$$


In this study, owing to the members of the supply chain system deciding to integrate and share resources for mutually beneficial cooperation, the joint total profit per unit of time (denoted by $\left.\operatorname{JTP}\left(T_{v}, q, n, \xi, p, M\right)\right)$ can be calculated as the sum of total profits of the vendor and the buyer, and is given by $\operatorname{JTP}\left(T_{v}, q, n, \xi, p, M\right)=T P_{b}(q, \xi, p, M)+T P_{v}\left(T_{v}, q, n, \xi, p, M\right)$. Due to the fact that $T_{v}=T_{p}+n T_{b}, \operatorname{JTP}\left(T_{v}, q, n, \xi, p, M\right)$ can be reduced as to $\operatorname{JTP}(q, n, \xi, p, M)$ from Equations (3) and (12).

The objective of this study is to ascertain the production, ordering, pricing, advertising, and investment policies of supply chain members under carbon tax and carbon capand-trade policies to maximize the total profit of production-inventory systems. The comprehensive total profit considering different carbon emission management strategies can be expressed as follows:

Carbon cap-and-trade

When considering a carbon cap-and-trade policy in which both the buyer and vendor have a $\omega_{b}$ and $\omega_{v}$ quotas for their total carbon emissions, if one of them exceeds the quota, the excess carbon must be purchased at the market price $p_{c}$. By contrast, the rest can be sold for the same price if carbon emissions do not exceed the prescribed limit. Consequently, the total profit per unit of time under these circumstances (denoted by $\left.\operatorname{JT} P_{C C}(q, n, \xi, p, M)\right)$ is

$\left.J T P_{C C}(q, n, \xi, p, M)=J T P(q, n, \xi, p, M)-p_{c}\left\{\left[E_{b}(q, \xi, p, M)-\omega_{b}\right]+E_{v}(q, n, \xi, p, M)-\omega_{v}\right]\right\}$

\section{(2) Carbon tax}

In this situation, based on a simple linear tax schedule [13], supply chain members need to pay a monetary unit $C$ for each unit of carbon emitted. Therefore, the total profit per unit of time considering the carbon tax policy (denoted by $\operatorname{JTP}_{C T}(q, n, \xi, p, M)$ ) is

$$
J T P_{C T}(q, n, \xi, p, M)=J T P(q, n, \xi, p, M)-C\left[E_{b}(q, \xi, p, M)+E_{v}(q, n, \xi, p, M)\right]
$$

For each case, the optimal advertising, order quantity, pricing, shipment quantity, and investment of carbon emission reduction under different carbon strategies are ascertained so as to maximize the joint total profit function $J T P_{i}(q, n, \xi, p, M)$, where $i \in\{C C, C T\}$. Because $n_{i}$ is an integer, this study first obtains the values of $q, \xi, p$, and $M$ (denoted by $q_{i}^{\left(n_{i}\right)}, \xi_{i}^{\left(n_{i}\right)}, p_{i}^{\left(n_{i}\right)}$ and $\left.M_{i}^{\left(n_{i}\right)}\right)$ by solving the equations $\partial J T P_{i}\left(q, n_{i}, \xi, p, M\right) / \partial q=0$, $\partial J T P_{i}\left(q, n_{i}, \xi, p, M\right) / \partial \xi=0, \partial J T P_{i}\left(q, n_{i}, \xi, p, M\right) / \partial p=0$ and $\partial J T P_{i}\left(q, n_{i}, \xi, p, M\right) / \partial M=0$ for given $n_{i}$, where $i \in\{C C, C T\}$. Then, this paper applies the Hessian matrix to verify the concavity of the joint total profit function as shown below.

$$
H_{i}=\left[\begin{array}{llll}
\frac{\partial^{2} J T P_{i}(q, n, \xi, p, M)}{\partial q^{2}} & \frac{\partial^{2} J T P_{i}(q, n, \xi, p, M)}{\partial q \partial \xi} & \frac{\left.\partial^{2} J T P_{i}(q, n, \xi, p, M)\right)}{\partial q \partial p} & \frac{\partial^{2} J T P_{i}(q, n, \xi, p, M)}{\partial q \partial M} \\
\frac{\partial^{2} J T P_{i}(q, n, \xi, p, M)}{\partial \xi \partial q} & \frac{\partial^{2} J T P_{i}(q, n, \xi, p, M)}{\partial \xi^{2}} & \frac{\partial^{2} J T P_{i}(q, n, \xi, p, M)}{\partial \xi \partial p} & \frac{\partial^{2} J T P_{i}(q, n, \xi, p, M)}{\partial \xi \partial M} \\
\frac{\partial^{2} J T P_{i}(q, n, \xi, p, M)}{\partial p \partial q} & \frac{\partial^{2} J T P_{i}(q, n, \xi, p, M)}{\partial p \partial \xi} & \frac{\partial^{2} J T P_{i}(q, n, \xi, p, M)}{\partial p^{2}} & \frac{\partial^{2} J T P_{i}(q, n, \xi, p, M)}{\partial p \partial M} \\
\frac{\partial^{2} J T P_{i}(q, n, \xi, p, M)}{\partial M \partial q} & \frac{\partial^{2} J T P_{i}(q, n, \xi, p, M)}{\partial M \partial \xi} & \frac{\partial^{2} J T P_{i}(q, n, \xi, p, M)}{\partial M \partial p} & \frac{\partial^{2} J T P_{i}(q, n, \xi, p, M)}{\partial M^{2}}
\end{array}\right] .
$$

For the value of $\left(q_{i}^{\left(n_{i}\right)}, \xi_{i}^{\left(n_{i}\right)}, p_{i}^{\left(n_{i}\right)}, M_{i}^{\left(n_{i}\right)}\right)$, if the $j$ th determinants of the Hessian matrix (denoted by $\left|H_{i j}\right|$, where $i \in\{C C, C T\}$ and $\left.j \in\{1,2,3,4\}\right)$ satisfy $\left|H_{i 1}\right|_{\left(q=q_{i}^{(n)}, \tilde{\xi}_{\tilde{\xi}} \tilde{\xi}_{i}^{(n)}, p=p_{i}^{(n)},{ }_{\left.M=M_{i}^{(n)}\right)}<\right.}<$ $0, \quad\left|H_{i 2}\right|_{\left(q=q_{i}^{(n)}, \xi=\xi_{i}^{(n)}, p=p_{i}^{(n)}, M=M_{i}^{(n)}\right)}>0, \quad\left|H_{i 3}\right|_{\left(q=q_{i}^{(n)}, \xi_{=} \xi_{i}^{(n)}, p=p_{i}^{(n)}, M=M_{i}^{(n)}\right)}<0$ and $\left|H_{i 4}\right|_{\left(q=q_{i}^{(n)},{ }_{\tilde{\xi}}=\xi_{i}^{(n)}, p=p_{i}^{(n)}, M=M_{i}^{(n)}\right)}>0$, then the joint total profit function $J P_{i}(q, n, \xi, p, M)$ has a maximum value at the point $\left(q_{i}^{\left(n_{i}\right)}, \xi_{i}^{\left(n_{i}\right)}, p_{i}^{\left(n_{i}\right)}, M_{i}^{\left(n_{i}\right)}\right)$. Due to the complexity of the model, we performed alternate numerical analyses to confirm the concavity. Next, the following Algorithm 1 is developed for finding the optimal solutions of buyers and vendors with different carbon emission policies. 


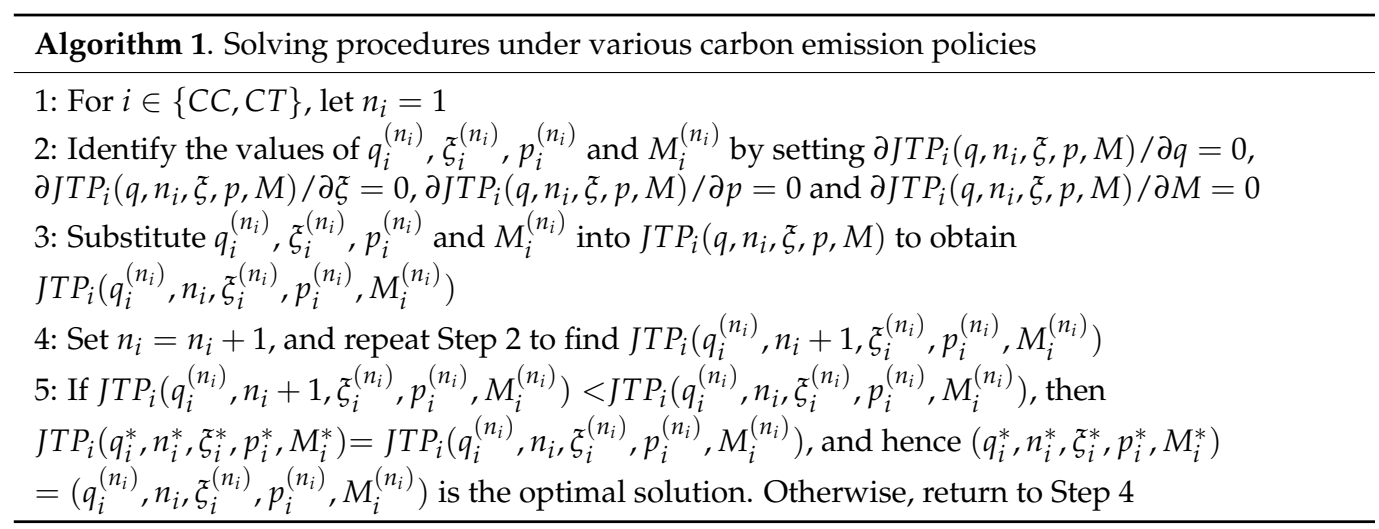

\section{Numerical Illustration and Sensitivity Analysis}

Example 1: Consider a production-inventory system under the carbon cap-and-trade policy in which $a=1500$ units/year, $b=15, P=3000$ units/year, $A=\$ 200$ /order, $\hat{A}=10 \mathrm{~kg} /$ order, $K=\$ 500 /$ order, $\hat{K}=100 \mathrm{~kg} /$ order, $S=\$ 800 / \mathrm{setup}$, $\hat{S}=150 \mathrm{~kg} /$ setup, $\hat{M}=0.01 \mathrm{~kg} /$ unit, $c=\$ 10 /$ unit, $\hat{c}=2 \mathrm{~kg} /$ unit, $c_{1}=\$ 2 /$ unit, $\hat{c}_{1}=0.5 \mathrm{~kg} /$ unit, $v=\$ 30 /$ unit, $\hat{v}=0.01 \mathrm{~kg} /$ unit, $h_{b}=\$ 0.5 /$ unit $/$ year, $\hat{h}_{b}=0.01 \mathrm{~kg} /$ unit/year, $h_{v}=\$ 0.3 /$ unit/year, $\hat{h}_{v}=0.01 \mathrm{~kg} /$ unit/year, $h_{m}=\$ 0.1 /$ unit/year, $\hat{h}_{m}=0.01 \mathrm{~kg} /$ unit/year, $\theta_{g}=0.1, \theta_{m}=0.05, C_{T}=\$ 50 /$ shipment, $\hat{C}_{T}=3 \mathrm{~kg} /$ shipment, $C_{t}=\$ 3 /$ unit, $\hat{C}_{t}=0.01 \mathrm{~kg} /$ unit, $\omega_{b}=5000 \mathrm{~kg} /$ year, $\omega_{v}=5000 \mathrm{~kg} /$ year, $p_{c}=\$ 0.5 /$ unit, $\mathrm{r}=1, \mathrm{a}=1500, \mathrm{~b}=15, \alpha=1, \beta=0.06$ and $\rho=0.5$. The values of this example refer to Lu et al. [20] and Pan et al. [21] with some additional parameters. By using the above algorithm, we obtained that the optimal number of shipments, shipping quantity, investment, selling price, and promotional cost for the entire supply chain system are $n_{C C}^{*}=3, q_{C C}^{*}=345.972$ units, $\xi_{C C}^{*}=\$ 89.3402, p_{C C}^{*}=\$ 72.6989$ and $M_{C C}^{*}=\$ 9.9365$. The optimal order quantity of buyer was $Q_{C C}^{*}=n_{C C}^{*} q_{C C}^{*}=1037.92$ units, and the optimal joint total profit $J T P_{C C}\left(q_{C C}^{*}, n_{C C}^{*}, \xi_{C C}^{*}, p_{C C}^{*}, M_{C C}^{*}\right)=\$ 21,092$. To verify the characteristics of the optimal solution, we check the values of $\left|H_{11}\right|_{\left(q_{C C}=345.972, \tilde{s}_{C C}=89.3402, p_{C C}=72.6889, M_{C C}=9.9365\right)}=-0.0384<0$,

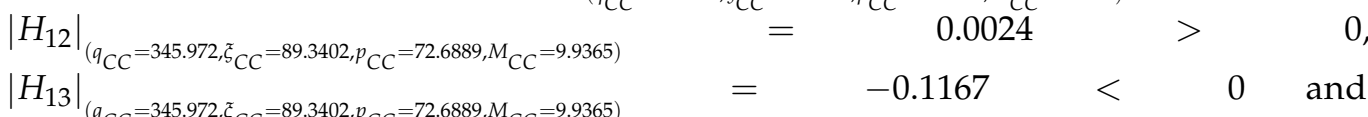
$\left|H_{14}\right|_{\left(q_{C C}=345.972, \xi_{C C}=89.3402, p_{C C}=72.6889, M_{C C}=9.9365\right)}=4.4469>0$ for $n_{C C}=3$. Further, Figure 3 illustrates the graphical illustration of the joint total profit function $J T P_{C C}\left(q_{C C}, n_{C C}, \xi_{C C}, p_{C C}, M_{C C}\right)$ versus $n_{C C}$ for $\left(q_{C C}, \xi_{C C}, p_{C C}, M_{C C}\right)=(345.972,89.3402$, $72.6989,9.9365)$. Therefore, the concavity of the joint total profit function can be verified, and the obtained solutions be guaranteed to optimal for maximizing the joint total profit of the supply chain system.

Example 2: Consider another production-inventory system with carbon tax policy where is similar as Example 1 except $C=\$ 0.1$ / unit. Appling the above-mentioned Algorithm, the optimal number of shipments, delivery quantity, investment, selling price and promotional cost for the entire supply chain system under the carbon tax policy are $n_{C T}^{*}=5, q_{C T}^{*}=231.469$ units, $\xi_{C T}^{*}=\$ 52.8458, p_{C T}^{*}=\$ 70.963$ and $M_{C T}^{*}=\$ 11.9297$. The buyer's optimal order quantity was $Q_{C T}^{*}=n_{C T}^{*} q_{C T}^{*}=1157.34$ units, and the optimal joint total profit $J T P_{C T}\left(q_{C T}^{*}, n_{C T}^{*}, \xi_{C T}^{*}, p_{C T}^{*}, M_{C T}^{*}\right)=\$ 20,028.6$. To verify the characteristics of the optimal solution, we check the values of $\left|H_{21}\right|_{\left(q_{C T}=231.469, \xi_{C T}=52.8458, p_{C T}=70.9630, M_{C T}=11.9297\right)}=$ $-0.0779<0,\left|H_{22}\right|_{\left(q_{C T}=231.469, \xi_{C T}=52.8458, p_{C T}=70.9630, M_{C T}=11.9297\right)}=0.0076>0$

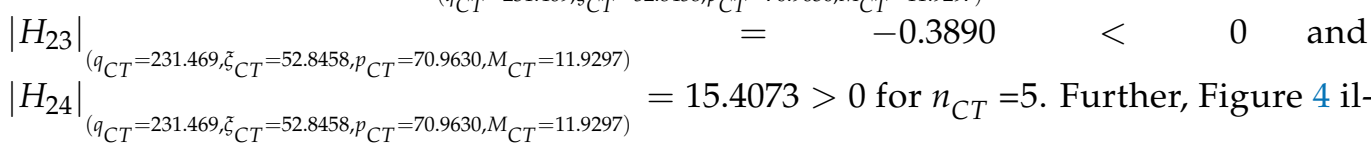


lustrates the graphical illustration of the joint total profit function $J T P_{C T}\left(q_{C T}, n_{C T}, \xi_{C T}, p_{C T}, M_{C T}\right)$ versus $n_{C T}$ for $\left(q_{C T}, \xi_{C T}, p_{C T}, M_{C T}\right)=(231.496,52.8458$, $70.9360,11.9297)$. Therefore, the concavity of the joint total profit function can be also verified.

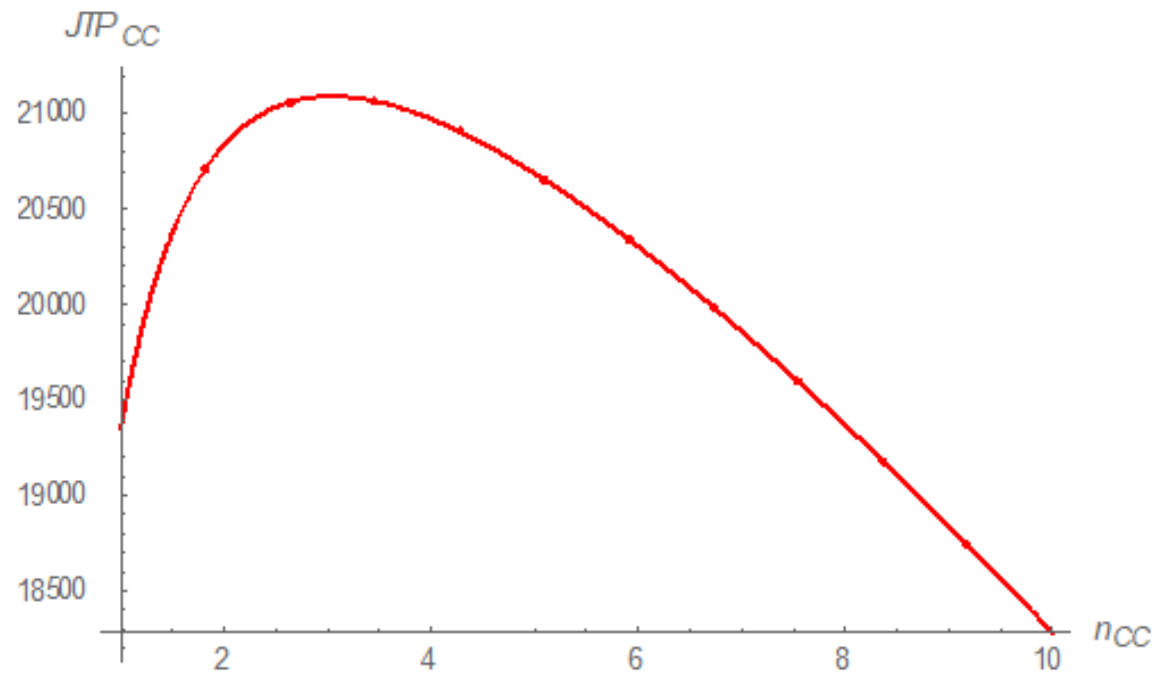

Figure 3. Graphical illustration $J T P_{C C}\left(q_{C C}, n_{C C}, \xi_{C C}, p_{C C}, M_{C C}\right)$ of versus $n_{C C}$ for $\left(q_{C C}, \xi_{C C}, p_{C C}, M_{C C}\right)=(345.972,89.3402,72.6989,9.9365)$.

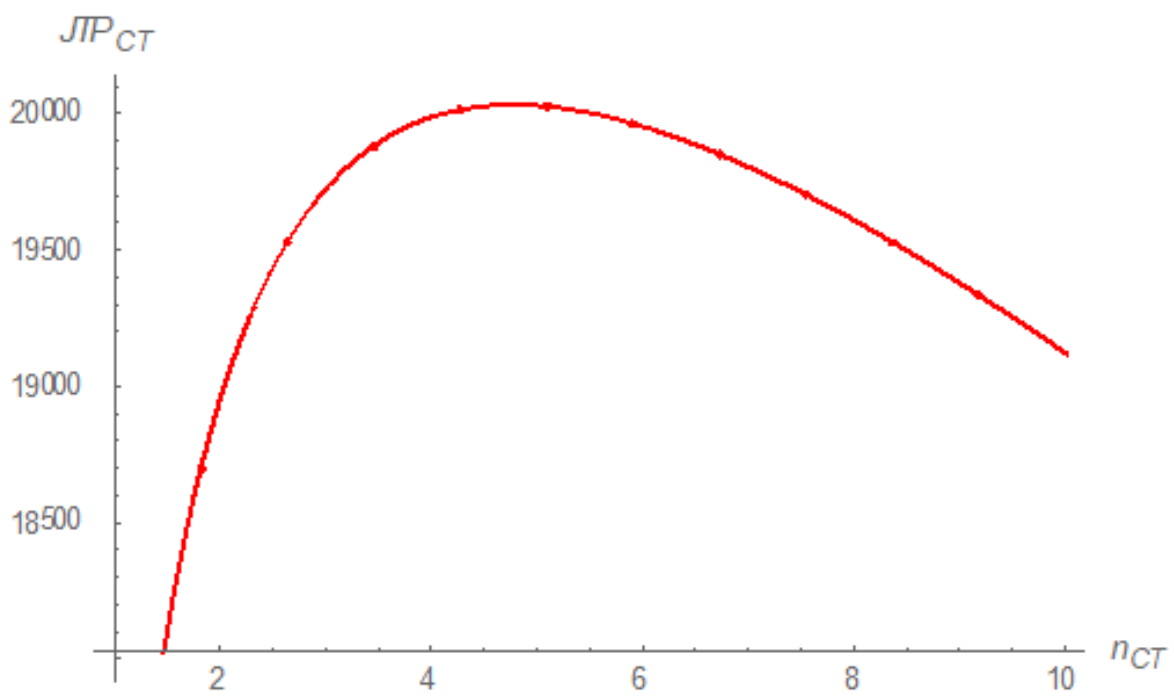

Figure 4. Graphical illustration $J T P_{C T}\left(q_{C T}, n_{C T}, \xi_{C T}, p_{C T}, M_{C T}\right)$ of versus $n_{C T}$ for $\left(q_{C T}, \xi_{C T}, p_{C T}, M_{C T}\right)=(231.496,52.8458,70.9360,11.9297)$.

Example 3: In this example, the impacts of model parameters on the optimal solutions are performed based on Example 1. Each parameter is changed by $+20 \%,+10 \%,-10 \%$, and $-20 \%$ at a time while the remaining parameters are kept unchanged. The computation results of the sensitivity analysis are presented in Tables 2 and 3 . According to the results in Table 2, the following observations can be drawn:

(1) Increasing the production rate or deteriorating rate of finished product reduces the vendor's shipping quantity of order quantities, the buyers' order quantities of finished products, unit selling price, and investment for carbon emissions reduction while increasing the buyer's unit promotional cost and the integrated total profit. The results indicate that when the productivity or the deteriorating rate of finished product increases, the demand can be increased by lowering prices and increasing advertising 
investment, thereby increasing the integrated total profit. It's worth noting that when considering pricing and advertising effectiveness, productivity increases will reduce the vendor's shipping quantity, which is different from the result of $[21,22]$. Further, the influence of the deteriorating rate of the finished product changing to the optimal solutions is particularly significant.

(2) Increasing the vendor's set up cost, ordering cost of raw materials, the buyer's ordering cost of finished products or fixed shipping cost increases their shipping quantity of order quantities, the buyers' order quantities of finished products, unit selling price, and investment for carbon emissions reduction but decreases the buyer's unit promotional cost and the integrated total profit. It is intuitive that the quantity of production and delivery will increase while the integrated total profit will decrease as fixed costs increase. However, investment for carbon emissions reduction and the selling price will increase while the advertising investment will decrease with increasing fixed costs.

(3) Increasing the unit cost parameters $c_{1}, v, h_{b}, h_{v}, h_{m}, C_{t}$, deteriorating rate of raw material or amount of raw materials used per unit of finished good decreases the vendor's shipping quantity of order quantities, the buyers' order quantities of finished products, unit promotional cost, investment in reducing carbon emissions reduction, and the integrated total profit, but increases the buyer's selling price.

(4) Although these results are intuitive, it's worth noting that when the change of vendor's production cost or supply price is large enough (for example, the vendor's production cost decreases by $20 \%$ or the vendor's supply price increases by $20 \%$ in Table 2), the optimal number of shipments will change.

(5) With the increase in scale demand parameter $a$ or the decrease in price elasticity factor $b$, all the vendor's shipping quantity of order quantities, the buyers' order quantities of finished products, unit selling price, unit promotional cost, and the investment in carbon emissions reduction and integrated total profit will increase under the fixed number of shipments. In addition, Benjaafar et al. [7] emphasized that determining the frequency of delivery is very important in mitigating carbon emissions, this study finds that the changes in demand parameters are relatively sensitive to the number of shipments.

(6) As to the advertisement effectiveness factors, all the vendor's shipping quantity of order quantities, the buyers' order quantities of finished products, investment for carbon emissions reduction, and the integrated total profit will increase with the increase in $\alpha$ or $\beta$. The difference is that the selling price and the advertising investment will increase as the value of $\alpha$ increases, but they will decrease as the value of $\beta$ increases. This result is different from $[25,26,28]$ because this study treats advertising cost as a decision variable.

Table 2. Sensitivity analysis of major parameters.

\begin{tabular}{|c|c|c|c|c|c|c|c|c|}
\hline \multirow{2}{*}{ Parameters } & \multirow{2}{*}{ Changing in \% } & \multirow{2}{*}{$n_{C C}^{*}$} & \multicolumn{6}{|c|}{ Changing in \% } \\
\hline & & & $q_{C C}^{*}$ & $Q_{C C}^{*}$ & $\xi_{C C}^{*}$ & $p_{C C}^{*}$ & $M_{C C}^{*}$ & $J T P_{C C}^{*}$ \\
\hline \multirow{4}{*}{$P$} & -20 & 3 & 0.1240 & 0.1233 & 0.0556 & 0.1820 & -1.3736 & -0.6021 \\
\hline & -10 & 3 & 0.0543 & 0.0540 & 0.0248 & 0.0823 & -0.6210 & -0.2717 \\
\hline & +10 & 3 & -0.0436 & -0.0443 & -0.0203 & -0.0692 & 0.5215 & 0.2266 \\
\hline & +20 & 3 & -0.0795 & -0.0800 & -0.0373 & -0.1281 & 0.9654 & 0.4191 \\
\hline \multirow{4}{*}{$S$} & -20 & 3 & -2.0051 & -2.0050 & -0.3708 & -0.0187 & 0.2801 & 0.4608 \\
\hline & -10 & 3 & -0.9963 & -0.9962 & -0.1836 & -0.0094 & 0.1394 & 0.2290 \\
\hline & +10 & 3 & 0.9842 & 0.9837 & 0.1801 & 0.0092 & -0.1379 & -0.2271 \\
\hline & +20 & 3 & 1.9568 & 1.9568 & 0.3566 & 0.0184 & -0.2745 & -0.4514 \\
\hline
\end{tabular}


Table 2. Cont

\begin{tabular}{|c|c|c|c|c|c|c|c|c|}
\hline \multirow{2}{*}{ Parameters } & \multirow{2}{*}{ Changing in $\%$} & \multirow{2}{*}{$n_{C C}^{*}$} & \multicolumn{6}{|c|}{ Changing in \% } \\
\hline & & & $q_{C C}^{*}$ & $Q_{C C}^{*}$ & $\xi_{C C}^{*}$ & $p_{C C}^{*}$ & $M_{C C}^{*}$ & $J T P_{C C}^{*}$ \\
\hline \multirow{4}{*}{$A$} & -20 & 3 & -1.5990 & -1.5994 & -0.2953 & -0.0188 & 0.2529 & 0.3708 \\
\hline & -10 & 3 & -0.7954 & -0.7958 & -0.1464 & -0.0094 & 0.1259 & 0.1844 \\
\hline & +10 & 3 & 0.7876 & 0.7872 & 0.1443 & 0.0094 & -0.1247 & -0.1830 \\
\hline & +20 & 3 & 1.5675 & 1.5676 & 0.2862 & 0.0186 & -0.2484 & -0.3646 \\
\hline \multirow{4}{*}{$K$} & -20 & 3 & -1.2472 & -1.2477 & -0.2300 & -0.0117 & 0.1744 & 0.2868 \\
\hline & -10 & 3 & -0.6211 & -0.6214 & -0.1143 & -0.0058 & 0.0870 & 0.1427 \\
\hline & +10 & 3 & 0.6165 & 0.6157 & 0.1129 & 0.0058 & -0.0863 & -0.1422 \\
\hline & +20 & 3 & 1.2284 & 1.2284 & 0.2245 & 0.0116 & -0.1722 & -0.2835 \\
\hline \multirow{4}{*}{$c$} & -20 & 4 & -6.4231 & 24.7688 & 0.1756 & -1.0488 & 8.2970 & 7.0439 \\
\hline & -10 & 3 & 3.8116 & 3.8115 & 0.6810 & -0.4318 & 2.9752 & 3.4643 \\
\hline & +10 & 3 & -3.5824 & -3.5831 & -0.6586 & 0.4348 & -3.0101 & -3.3852 \\
\hline & +20 & 3 & -6.9607 & -6.9609 & -1.2975 & 0.8729 & -6.0549 & -6.6912 \\
\hline \multirow{4}{*}{$c_{1}$} & -20 & 3 & 1.5900 & 1.5897 & 0.2867 & -0.1761 & 1.2100 & 1.3901 \\
\hline & -10 & 3 & 0.7891 & 0.7891 & 0.1428 & -0.0882 & 0.6058 & 0.6932 \\
\hline & +10 & 3 & -0.7781 & -0.7785 & -0.1415 & 0.0882 & -0.6071 & -0.6903 \\
\hline & +20 & 3 & -1.5452 & -1.5454 & -0.2818 & 0.1765 & -1.2155 & -1.3768 \\
\hline \multirow{4}{*}{$v$} & -20 & 3 & 1.3539 & 1.3537 & 0.2402 & -0.3803 & 2.7578 & 1.3569 \\
\hline & -10 & 3 & 0.6694 & 0.6696 & 0.1191 & -0.1884 & 1.3670 & 0.6718 \\
\hline & +10 & 3 & -0.6555 & -0.6561 & -0.1171 & 0.1853 & -1.3435 & -0.6590 \\
\hline & +20 & 4 & -14.6055 & 13.8585 & -1.4455 & 0.1476 & -0.0851 & -1.2920 \\
\hline \multirow{4}{*}{$h_{b}$} & -20 & 3 & 2.8109 & 2.8104 & 0.4938 & -0.9146 & 6.6646 & 6.4347 \\
\hline & -10 & 3 & 1.4044 & 1.4038 & 0.2482 & -0.4576 & 3.3345 & 3.1785 \\
\hline & +10 & 3 & -1.4027 & -1.4028 & -0.2503 & 0.4583 & -3.3394 & -3.1016 \\
\hline & +20 & 3 & -2.8037 & -2.8037 & -0.5031 & 0.9173 & -6.6840 & -6.1270 \\
\hline \multirow{4}{*}{$h_{v}$} & -20 & 3 & 0.9666 & 0.9664 & 0.1765 & -0.0127 & 0.0275 & 0.1887 \\
\hline & -10 & 3 & 0.4798 & 0.4798 & 0.0878 & -0.0063 & 0.0139 & 0.0939 \\
\hline & +10 & 3 & -0.4729 & -0.4731 & -0.0867 & 0.0062 & -0.0141 & -0.0939 \\
\hline & +20 & 3 & -0.9391 & -0.9394 & -0.1726 & 0.0125 & -0.0284 & -0.1873 \\
\hline \multirow{4}{*}{$h_{m}$} & -20 & 3 & 0.0902 & 0.0896 & 0.0166 & -0.0030 & 0.0158 & 0.0137 \\
\hline & -10 & 3 & 0.0451 & 0.0443 & 0.0083 & -0.0015 & 0.0080 & 0.0066 \\
\hline & +10 & 3 & -0.0451 & -0.0453 & -0.0082 & 0.0015 & -0.0078 & -0.0071 \\
\hline & +20 & 3 & -0.0902 & -0.0906 & -0.0165 & 0.0029 & -0.0157 & -0.0137 \\
\hline \multirow{4}{*}{$\theta_{g}$} & -20 & 3 & 10.2138 & 10.2137 & 13.3196 & 2.9028 & -20.9241 & -18.2249 \\
\hline & -10 & 3 & 5.1539 & 5.1536 & 6.2303 & 1.1960 & -8.5922 & -7.8361 \\
\hline & +10 & 3 & -4.8131 & -4.8135 & -5.4609 & -0.8776 & 6.2581 & 6.0065 \\
\hline & +20 & 3 & -9.1718 & -9.1722 & -10.2543 & -1.5449 & 10.9740 & 10.6879 \\
\hline \multirow{4}{*}{$\theta_{m}$} & -20 & 3 & 0.1000 & 0.0992 & 0.0171 & -0.0033 & 0.0174 & 0.0152 \\
\hline & -10 & 3 & 0.0500 & 0.0491 & 0.0086 & -0.0017 & 0.0088 & 0.0076 \\
\hline & +10 & 3 & -0.0500 & -0.0501 & -0.0085 & 0.0017 & -0.0087 & -0.0076 \\
\hline & +20 & 3 & -0.1003 & -0.1002 & -0.0170 & 0.0032 & -0.0173 & -0.0152 \\
\hline \multirow{4}{*}{$C_{T}$} & -20 & 3 & -0.3969 & -0.3969 & -0.0729 & -0.0047 & 0.0628 & 0.0920 \\
\hline & -10 & 3 & -0.1983 & -0.1985 & -0.0364 & -0.0023 & 0.0314 & 0.0460 \\
\hline & +10 & 3 & 0.1977 & 0.1975 & 0.0364 & 0.0023 & -0.0312 & -0.0460 \\
\hline & +20 & 3 & 0.3948 & 0.3941 & 0.0724 & 0.0047 & -0.0625 & -0.0920 \\
\hline \multirow{4}{*}{$C_{t}$} & -20 & 3 & 0.9602 & 0.9596 & 0.1706 & -0.2770 & 2.0101 & 1.9221 \\
\hline & -10 & 3 & 0.4795 & 0.4788 & 0.0854 & -0.1385 & 1.0057 & 0.9577 \\
\hline & +10 & 3 & -0.4789 & -0.4788 & -0.0854 & 0.1385 & -1.0059 & -0.9506 \\
\hline & +20 & 3 & -0.9567 & -0.9567 & -0.1710 & 0.2772 & -2.0124 & -1.8946 \\
\hline \multirow{4}{*}{$a$} & -20 & 2 & -6.0704 & -37.3805 & -3.4529 & -18.1491 & -70.2065 & -47.6204 \\
\hline & -10 & 3 & -12.3056 & -12.3061 & -2.2821 & -9.1802 & -33.4552 & -27.3336 \\
\hline & +10 & 3 & 11.9053 & 11.9046 & 2.0144 & 9.2413 & 33.0271 & 34.9256 \\
\hline & +20 & 4 & 8.2677 & 44.3560 & 2.6941 & 18.2633 & 68.5639 & 79.0129 \\
\hline
\end{tabular}


Table 2. Cont.

\begin{tabular}{|c|c|c|c|c|c|c|c|c|}
\hline \multirow{2}{*}{ Parameters } & \multirow{2}{*}{ Changing in $\%$} & \multirow{2}{*}{$n_{C C}^{*}$} & \multicolumn{6}{|c|}{ Changing in \% } \\
\hline & & & $q_{C C}^{*}$ & $Q_{C C}^{*}$ & $\xi_{C C}^{*}$ & $p_{C C}^{*}$ & $M_{C C}^{*}$ & $J T P_{C C}^{*}$ \\
\hline \multirow{4}{*}{$b$} & -20 & 4 & 0.2835 & 33.7107 & 1.3254 & 22.7981 & 85.0788 & 66.3446 \\
\hline & -10 & 4 & -7.1315 & 23.8236 & -0.0109 & 10.0422 & 39.0021 & 26.9306 \\
\hline & +10 & 3 & -6.3806 & -6.3810 & -1.1520 & -8.3458 & -30.1238 & -19.2054 \\
\hline & +20 & 3 & -12.2481 & -12.2483 & -2.2646 & -15.2819 & -55.3401 & -33.2534 \\
\hline \multirow{4}{*}{$\alpha$} & -20 & 3 & -5.2730 & -5.2733 & -0.9594 & 1.5436 & 22.3392 & -10.1721 \\
\hline & -10 & 3 & -2.6493 & -2.6495 & -0.4771 & 0.7707 & 11.1783 & -5.1930 \\
\hline & +10 & 3 & 2.6759 & 2.6755 & 0.4721 & -0.7686 & -11.1935 & 5.4096 \\
\hline & +20 & 3 & 5.3802 & 5.3800 & 0.9394 & -1.5354 & -22.4016 & 11.0412 \\
\hline \multirow{4}{*}{$\beta$} & -20 & 3 & -5.4704 & -5.4707 & -0.9835 & -1.9722 & -28.3606 & -5.7472 \\
\hline & -10 & 3 & -2.7572 & -2.7574 & -0.4909 & -0.8790 & -12.5963 & -3.0343 \\
\hline & +10 & 3 & 2.7635 & 2.7632 & 0.4826 & 0.7235 & 10.2867 & 3.2610 \\
\hline & +20 & 3 & 5.5111 & 5.5110 & 0.9533 & 1.3310 & 18.8360 & 6.6878 \\
\hline \multirow{4}{*}{$r$} & -20 & 3 & 1.8212 & 1.8209 & 0.2038 & -0.1938 & 1.3277 & 1.5219 \\
\hline & -10 & 3 & 0.9024 & 0.9018 & 0.1013 & -0.0970 & 0.6645 & 0.7591 \\
\hline & +10 & 3 & -0.8868 & -0.8874 & -0.0998 & 0.0970 & -0.6660 & -0.7548 \\
\hline & +20 & 3 & -1.7585 & -1.7593 & -0.1986 & 0.1942 & -1.3337 & -1.5058 \\
\hline
\end{tabular}

Gautam and Khanna [17] formulated a production-inventory model in which the cost of carbon emissions is only adhered to by the vendor and found that changes in the cost of carbon emissions will not affect the buyer's decision. This research not only considers the carbon emissions of the vendor and buyer at the same time, but also explores the impact of carbon emissions from various operating activities on the optimal solutions. Let us now consider the sensitivity analysis for carbon emission parameters as shown in Table 3. Although the changes in carbon emission parameters have a negative impact on total profits, which is the same as the previous research [18,21,22], this study also explores its impact on pricing and advertising decisions. The following observations can be drawn from Table 3.

(1) As the amount of fixed carbon emissions $\hat{A}, \hat{K}, \hat{S}$, or $\hat{C}_{T}$ increases, the vendor's shipping quantity of order quantities, the buyers' order quantities of finished products, unit selling price, and the investment in carbon emissions reduction increase, but the unit promotional cost of buyer and the integrated total profit decreases.

(2) As the amount of unit carbon emissions $\hat{c}, \hat{M}, \hat{c}_{1}, \hat{v}, \hat{h}_{b}, \hat{h}_{v}$ or $\hat{C}_{t}$ increases, the vendor's shipping quantity of order quantities, the buyers' order quantities of finished products, unit promotional cost and the integrated total profit decrease, but the unit selling price and the investment in carbon emissions reduction increases.

(3) With the increase in carbon emissions of vendor's unit raw material, the vendor's order quantity shipment, the buyer's finished product order quantity, unit promotional cost, the investment in carbon emissions reduction and the integrated total profit will decrease, but the unit selling price will increase.

(4) With the increase in carbon emissions, market price $p_{c}$, the vendor's shipping quantity of order quantities, the buyers' order quantities of finished products, unit selling price, the investment in carbon emissions reduction and the integrated total profit will increase, but the unit promotional cost will increase. 
Table 3. Robust check (sensitivity analysis) of carbon-emission-related parameters.

\begin{tabular}{|c|c|c|c|c|c|c|c|c|}
\hline \multirow{2}{*}{ Parameters } & \multirow{2}{*}{ Changing in \% } & \multirow{2}{*}{$n_{C C}^{*}$} & \multicolumn{6}{|c|}{ Changing in \% } \\
\hline & & & $q_{C C}^{*}$ & $Q_{C C}^{*}$ & $\xi_{C C}^{*}$ & $p_{C C}^{*}$ & $M_{C C}^{*}$ & $J T P_{C T}^{*}$ \\
\hline \multirow{4}{*}{$\hat{A}$} & -20 & 3 & -2.7147 & -2.7150 & -1.1827 & -0.0315 & 0.4255 & 0.6254 \\
\hline & -10 & 3 & -1.3452 & -1.3460 & -0.5814 & -0.0157 & 0.2111 & 0.3101 \\
\hline & +10 & 3 & 1.3224 & 1.3219 & 0.5628 & 0.0154 & -0.2079 & -0.3063 \\
\hline & +20 & 3 & 2.6228 & 2.6226 & 1.1081 & 0.0307 & -0.4129 & -0.6078 \\
\hline \multirow{4}{*}{$\hat{K}$} & -20 & 3 & -0.0835 & -0.0838 & -0.0356 & -0.0008 & 0.0117 & 0.0190 \\
\hline & -10 & 3 & -0.0419 & -0.0424 & -0.0177 & -0.0004 & 0.0058 & 0.0095 \\
\hline & +10 & 3 & 0.0416 & 0.0414 & 0.0179 & 0.0004 & -0.0057 & -0.0095 \\
\hline & +20 & 3 & 0.0832 & 0.0829 & 0.0356 & 0.0007 & -0.0116 & -0.0194 \\
\hline \multirow{4}{*}{$\hat{S}$} & -20 & 3 & -0.1252 & -0.1253 & -0.0534 & -0.0012 & 0.0174 & 0.0284 \\
\hline & -10 & 3 & -0.0627 & -0.0626 & -0.0266 & -0.0006 & 0.0088 & 0.0142 \\
\hline & +10 & 3 & 0.0624 & 0.0617 & 0.0268 & 0.0006 & -0.0087 & -0.0147 \\
\hline & +20 & 3 & 0.1249 & 0.1243 & 0.0534 & 0.0011 & -0.0173 & -0.0289 \\
\hline \multirow{4}{*}{$\hat{c}$} & -20 & 3 & 0.4867 & 0.4866 & -0.4050 & -0.0579 & 0.4003 & 0.4599 \\
\hline & -10 & 3 & 0.2428 & 0.2428 & -0.2010 & -0.0290 & 0.2003 & 0.2295 \\
\hline & +10 & 3 & -0.2419 & -0.2428 & 0.1983 & 0.0289 & -0.2004 & -0.2295 \\
\hline & +20 & 3 & -0.4830 & -0.4837 & 0.3939 & 0.0579 & -0.4008 & -0.4585 \\
\hline \multirow{4}{*}{$\hat{M}$} & -20 & 3 & 0.1023 & 0.1021 & -0.2092 & -0.0309 & 0.2244 & 0.2134 \\
\hline & -10 & 3 & 0.0512 & 0.0511 & -0.1042 & -0.0154 & 0.1122 & 0.1067 \\
\hline & +10 & 3 & -0.0512 & -0.0520 & 0.1038 & 0.0154 & -0.1122 & -0.1067 \\
\hline & +20 & 3 & -0.1023 & -0.1031 & 0.2068 & 0.0308 & -0.2244 & -0.2134 \\
\hline \multirow{4}{*}{$\hat{c}_{1}$} & -20 & 3 & 0.1289 & 0.1281 & -0.1000 & -0.0147 & 0.1014 & 0.1157 \\
\hline & -10 & 3 & 0.0645 & 0.0636 & -0.0498 & -0.0074 & 0.0508 & 0.0578 \\
\hline & +10 & 3 & -0.0645 & -0.0646 & 0.0499 & 0.0073 & -0.0507 & -0.0583 \\
\hline & +20 & 3 & -0.1286 & -0.1291 & 0.0994 & 0.0147 & -0.1014 & -0.1162 \\
\hline \multirow{4}{*}{$\hat{v}$} & -20 & 3 & 0.1023 & 0.1021 & -0.2092 & -0.0309 & 0.2244 & 0.2134 \\
\hline & -10 & 3 & 0.0512 & 0.0511 & -0.1042 & -0.0154 & 0.1122 & 0.1067 \\
\hline & +10 & 3 & -0.0512 & -0.0520 & 0.1038 & 0.0154 & -0.1122 & -0.1067 \\
\hline & +20 & 3 & -0.1023 & -0.1031 & 0.2068 & 0.0308 & -0.2244 & -0.2134 \\
\hline \multirow{4}{*}{$\hat{h}_{b}$} & -20 & 3 & 1.0307 & 1.0299 & -2.2330 & -0.3117 & 2.2657 & 2.1714 \\
\hline & -10 & 3 & 0.5154 & 0.5145 & -1.0823 & -0.1558 & 1.1335 & 1.0810 \\
\hline & +10 & 3 & -0.5156 & -0.5155 & 1.0209 & 0.1558 & -1.1334 & -1.0720 \\
\hline & +20 & 3 & -1.0310 & -1.0319 & 1.9863 & 0.3118 & -2.2672 & -2.1349 \\
\hline \multirow{4}{*}{$\hat{h}_{v}$} & -20 & 3 & 0.0107 & 0.0106 & -0.0002 & -0.00014 & 0.0004 & 0.0019 \\
\hline & -10 & 3 & 0.0052 & 0.0048 & -0.0001 & -0.00007 & 0.0002 & 0.0009 \\
\hline & +10 & 3 & -0.0052 & -0.0058 & 0.0002 & 0.00007 & -0.0001 & -0.0009 \\
\hline & +20 & 3 & -0.0107 & -0.0106 & 0.0003 & 0.00014 & -0.0003 & -0.0024 \\
\hline \multirow{4}{*}{$\hat{h}_{m}$} & -20 & 3 & 0.0030 & 0.0030 & 0.0004 & -0.00010 & 0.0005 & 0.0005 \\
\hline & -10 & 3 & 0.0015 & 0.0015 & 0.00001 & -0.00005 & 0.0003 & 0.0002 \\
\hline & +10 & 3 & -0.0015 & -0.0015 & -0.00006 & 0.00005 & -0.0003 & -0.0002 \\
\hline & +20 & 3 & -0.0030 & -0.0030 & -0.00009 & 0.00010 & -0.0005 & -0.0005 \\
\hline \multirow{4}{*}{$\hat{C}_{T}$} & -20 & 3 & -0.8044 & -0.8045 & -0.3464 & -0.0094 & 0.1263 & 0.1854 \\
\hline & -10 & 3 & -0.4012 & -0.4018 & -0.1724 & -0.0047 & 0.0630 & 0.0925 \\
\hline & +10 & 3 & 0.3992 & 0.3989 & 0.1708 & 0.0047 & -0.0627 & -0.0925 \\
\hline & +20 & 3 & 0.7960 & 0.7958 & 0.3398 & 0.0092 & -0.1251 & -0.1844 \\
\hline \multirow{4}{*}{$\hat{C}_{t}$} & -20 & 3 & 0.1023 & 0.1021 & -0.2092 & -0.0309 & 0.2244 & 0.2134 \\
\hline & -10 & 3 & 0.0512 & 0.0511 & -0.1042 & -0.0154 & 0.1122 & 0.1067 \\
\hline & +10 & 3 & -0.0512 & -0.0520 & 0.1038 & 0.0154 & -0.1122 & -0.1067 \\
\hline & +20 & 3 & -0.1023 & -0.1031 & 0.2068 & 0.0308 & -0.2244 & -0.2134 \\
\hline \multirow{4}{*}{$p_{c}$} & -20 & 3 & -1.8889 & -1.8894 & -5.3529 & -0.5186 & 4.0178 & -0.4547 \\
\hline & -10 & 3 & -0.8989 & -0.8989 & -2.5284 & -0.2596 & 2.0081 & -0.2442 \\
\hline & +10 & 3 & 0.8139 & 0.8132 & 2.2873 & 0.2601 & -2.0082 & 0.2769 \\
\hline & +20 & 3 & 1.5487 & 1.5483 & 4.3740 & 0.5208 & -4.0166 & 0.5855 \\
\hline
\end{tabular}




\section{Conclusions}

From previous studies $[13,15]$, it is observed that investment in carbon emission reduction not only contributes to the increase in profits, but also effectively reduces the amount of carbon emissions. This study further developed a sustainable production-inventory model with advertisement- and price-dependent demand in a multi-stage supply chain to discuss the effects of pricing, advertising, and investment at the same time. The present study aimed to clearly determine the production and delivery, replenishment, investment, pricing, and advertising strategies to maximize the integrated total profit of the entire supply chain system. An algorithm was proposed to obtain the optimal solutions and total profit. Numerical examples and sensitivity analysis were conducted to verify the characteristics of the optimal solutions and obtain managerial insights different from previous research as follows:

(1) Whether the productivity or the deteriorating rate of finished product increases, supply chain members will reduce selling price and increase advertising investment in the demand, thereby increasing the integrated total profit. The effect is more significant when the deteriorating rate of finished product changes.

(2) Benjaafar et al. [7] claimed that the frequency of vendor 's delivery is very important in mitigating carbon emissions, and this study finds that the optimal the number of shipments is not easily affected by parameter changes, except for the vendor's production cost, supply price, and demand parameters.

(3) Different from the research of $[25,26,28]$, this study treats advertising costs as a decision variable. Changes in the advertisement effectiveness factors have the same effects on the vendor's shipping quantity of order quantities, the buyers' order quantities of finished products, investment for carbon emissions reduction, and the integrated total profit. However, their changes have opposite effects on the selling price and the advertising investment.

(4) When pricing, advertising and carbon emissions are considered in the model simultaneously and it is found that the increase in carbon emission parameter or mark price of carbon will increase the price, but will reduce the advertising investment.

This study puts forward a more realistic modeling hypothesis, which is beneficial to academic research, and the research conclusion can provide a useful reference for decision makers in practical applications. Nevertheless, the proposed model still has some research limitations. First, this study assumes that the buyer and seller's decisions are independent, though both parties jointly decide on production and delivery, replenishment, investment, pricing, and advertising strategies. Second, the transaction conditions of the buyer and seller to adopt cash on delivery are considered in this study. Finally, whether it is the finished products and materials of the buyer or the vendor, the deteriorating rate is a constant and shortages are not permitted.

Therefore, there are still some critical issues worth investigating for future research. For instance, the proposed model can be discussed with game theory including single leader and single (multiple) follower(s) in the supply chain system. Moreover, it could be interesting to add trade credit issues into the proposed model in future research. In addition, this study can also be extended to more general scenarios such as variable deteriorating rate, considering quantity discounts or allowing shortages.

Author Contributions: Conceptualization, J.-L.P. and C.-Y.C.; formal analysis, J.-L.P., K.-S.W. and C.-T.Y.; methodology, J.-L.P. and K.-S.W.; software, C.-T.Y.; supervision, C.-Y.C.; writing-original draft, J.-L.P., C.-Y.C., K.-S.W., C.-T.Y. and Y.-W.W. All authors have read and agreed to the published version of the manuscript.

Funding: This work is partially supported by the Ministry of Science and Technology, Taiwan, under grant number MOST 110-2410-H-231-001-MY2.

Institutional Review Board Statement: Not applicable.

Informed Consent Statement: Not applicable. 
Data Availability Statement: Not applicable.

Acknowledgments: The authors would like to thank the editor and anonymous reviewers for their valuable and constructive comments, which have led to a significant improvement in the manuscript.

Conflicts of Interest: The authors declare no conflict of interest.

\section{Notation}

$P \quad$ Production rate for the vendor

$D(p, M) \quad$ Demand rate for the buyer, a function of the selling price and advertisement cost

A Buyer's replenishment cost per order

$\hat{A} \quad$ Buyer's fixed carbon emissions per order

$K \quad$ Vendor's ordering cost of raw material per order

$\hat{K} \quad$ The fixed carbon emissions per order by the vendor

$r \quad$ Quantity of raw materials used per unit of finished good

$S \quad$ Vendor's setup cost per setup

$\hat{S} \quad$ Vendor's fixed carbon emissions per setup

c Product cost per unit for the vendor

$c_{1} \quad$ Material cost per unit for the vendor

$\hat{c} \quad$ The relative carbon emissions per unit of produced by the vendor

$\hat{c}_{1} \quad$ The relative carbon emissions per unit of material by the vendor

$v \quad$ The supply price per unit by the vendor

$\hat{v} \quad$ The carbon emissions associated with each unit purchased by the buyer

$\hat{M} \quad$ Amount of associated carbon emissions per unit of advertising for the buyer

$\theta_{m} \quad$ Deteriorating rate of raw materials

$\theta_{g} \quad$ Deteriorating rate of finished goods

$h_{b} \quad$ Buyer's carrying cost per unit of time

$\hat{h}_{b} \quad$ Carbon emissions per unit of inventory held by the buyer per unit of time

$h_{v} \quad$ The carrying cost per finished product per unit of time by vendor

$\hat{h}_{v} \quad$ The carbon emissions per finished product per unit of time by vendor

$h_{m} \quad$ The holding cost per unit of material per unit of time by vendor

$\hat{h}_{m} \quad$ The carbon emissions per unit of raw material per unit of time by vendor

$C_{T} \quad$ The fixed transportation cost per shipment by buyer

$\hat{C}_{T} \quad$ Buyer's fixed carbon emissions per shipment

$C_{t} \quad$ Buyer's variable transportation cost per unit

$\hat{C}_{t} \quad$ Buyer's associated carbon emissions per unit of transport

C Unit carbon emission tax rate

$\omega_{b} \quad$ Buyer's carbon emission quota per unit time

$\omega_{v} \quad$ Vendor's carbon emission quota per unit time

$\xi \quad$ Carbon emissions reduction investment, a decision variable

$m(\xi) \quad$ Carbon emissions reduction ratio, as a function of

$v \quad$ Buyer's retail price per unit, a decision variable

$Q \quad$ Buyer's order quantity of finish products, a decision variable

$T_{p} \quad$ Length of time for the vendor to ship the finished products to the buyer for the

Tp first time, a decision variable

$T_{b} \quad$ Length of the replenishment cycle by the buyer, a decision variable

$T_{v} \quad$ Length of the production cycle by the vendor, a decision variable

$T_{S} \quad$ Length of the period of production by the vendor, a decision variable

M Buyer's promotional cost per unit, a decision variable

$n \quad$ Number of shipments from vendor to buyer, a decision variable

$q \quad$ Quantity per each transport from vendor to buyer, a decision variable

$Q_{m} \quad$ Vendor's order quantity of materials, a decision variable

* Superscript represents optimal value 


\section{References}

1. Bouchery, Y.; Ghaffari, A.; Jemai, Z.; Dallery, Y. Including sustainability criteria into inventory models. Eur. J. Oper. Res. 2012, 222, 229-240. [CrossRef]

2. Gong, R.; Xue, J.; Zhao, L.; Zolotova, O.; Ji, X.; Xu, Y. A bibliometric analysis of green supply chain management based on the Web of Science (WOS) platform. Sustainability 2019, 11, 3459. [CrossRef]

3. Zimon, D.; Tyan, J.; Sroufe, R. Implementing sustainable supply chain management: Reactive, cooperative, and dynamic models. Sustainability 2019, 11, 7227. [CrossRef]

4. Baghizadeh, K.; Zimon, D.; Jum'a, L. Modeling and optimization sustainable forest supply chain considering discount in transportation system and supplier selection under uncertainty. Forests 2021, 12, 964. [CrossRef]

5. Ahi, P.; Searcy, C. A comparative literature analysis of definitions for green and sustainable supply chain management. J. Clean. Prod. 2013, 52, 329-341. [CrossRef]

6. Kusi-Sarpong, S.; Gupta, H.; Sarkis, J. A supply chain sustainability innovation framework and evaluation methodology. Int. J. Prod. Res. 2019, 57, 1990-2008. [CrossRef]

7. Benjaafar, S.; Li, Y.; Daskin, M. Carbon footprint and the management of supply chain: Insights from simple models. IEEE Trans. Autom. Sci. Eng. 2013, 10, 99-116. [CrossRef]

8. Zimon, D.; Tyan, J.; Sroufe, R. Drivers of sustainable supply chain management: Practices to alignment with un sustainable development goals. Int. J. Qual. Res. 2020, 14, 219-236. [CrossRef]

9. Uygun, Ö.; Dede, A. Performance evaluation of green supply chain management using integrated fuzzy multi-criteria decision making techniques. Comput. Ind. Eng. 2016, 102, 502-511. [CrossRef]

10. Arslan, M.C.; Turkay, M. EOQ revisited with sustainability considerations. Found. Comput. Decis. Sci. 2013, 38, 223-249. [CrossRef]

11. Chen, X.; Benjaafar, S.; Elomri, A. The carbon-constrained EOQ. Oper. Res. Lett. 2013, 41, 172-179. [CrossRef]

12. Battini, D.; Persona, A.; Sgarbossa, F. A sustainable EOQ model: Theoretical formulation and applications. Int. J. Prod. Econ. 2014, 149, 145-153. [CrossRef]

13. Toptal, A.; Özlü, H.; Konur, D. Joint decisions on inventory replenishment and emission reduction investment under different emission regulations. Int. J. Prod. Res. 2014, 52, 243-269. [CrossRef]

14. Taleizadeh, A.A.; Soleymanfar, V.R.; Govindan, K. Sustainable economic production quantity models for inventory systems with shortage. J. Clean. Prod. 2018, 174, 1011-1020. [CrossRef]

15. Hammami, R.; Nouira, I.; Frein, Y. Carbon emissions in a multi-echelon production-inventory model with lead time constraints. Int. J. Prod. Econ. 2015, 164, 292-307. [CrossRef]

16. Datta, T.K. Effect of green technology investment on a production-inventory system with carbon tax. Adv. Oper. Res. 2017, 2017, 1-13. [CrossRef]

17. Gautam, P.; Khanna, A. An imperfect production inventory model with setup cost reduction and carbon emission for an integrated supply chain. Uncertain Supply Chain Manag. 2018, 6, 271-286. [CrossRef]

18. Shen, Y.J.; Shen, K.F.; Yang, C.T. A production inventory model for deteriorating items with collaborative preservation technology investment under carbon tax. Sustainability 2019, 11, 5027. [CrossRef]

19. Asghar, I.; Sarkar, B.; Kim, S.J. Economic analysis of an integrated production-inventory system under stochastic production capacity and energy consumption. Energies 2019, 12, 3179. [CrossRef]

20. Zavanella, L.E.; Marchi, B.; Zanoni, S.; Ferretti, I. Energy considerations for the economic production quantity and the joint economic lot sizing. J. Bus. Econ. 2019, 89, 845-865. [CrossRef]

21. Chen, Z.; Bidanda, B. Sustainable manufacturing production-inventory decision of multiple factories with JIT logistics, component recovery and emission control. Transp. Res. E Logist. Transp. Rev. 2019, 128, 356-383. [CrossRef]

22. Lu, C.J.; Yang, C.T.; Yen, H.F. Stackelberg game approach for sustainable production-inventory model with collaborative investment in technology for reducing carbon emissions. J. Clean. Prod. 2020, 270, 121963. [CrossRef]

23. Pan, J.; Chiu, C.Y.; Wu, K.S.; Yen, H.F.; Wang, Y.W. Sustainable production-inventory model in technical cooperation on investment to reduce carbon emissions. Processes 2020, 8, 1438. [CrossRef]

24. Sepehria, A.; Gholamian, M.R. Joint pricing and lot-sizing for a production model under controllable deterioration and carbon emissions. Int. J. Syst. Sci. Oper. Logistics 2021, in press. [CrossRef]

25. Das, B.C.; Das, B.; Mondal, S.K. An integrated inventory model with delay in payment for deteriorating item under Weibull distribution and advertisement cum price-dependent demand. Int. J. Oper. Res. 2014, 20, 341-368. [CrossRef]

26. Geetha, K.V.; Udayakumar, R. Optimal lot sizing policy for non-instantaneous deteriorating items with price and advertisement dependent demand under partial backlogging. Int. J. Appl. Comput. 2016, 2, 171-193. [CrossRef]

27. Soni, H.N.; Chauhan, A.D. Joint pricing, inventory, and preservation decisions for deteriorating items with stochastic demand and promotional efforts. J. Ind. Eng. Int. 2018, 14, 831-843. [CrossRef]

28. Soni, H.N.; Suthar, D.N. Pricing and inventory decisions for non-instantaneous deteriorating items with price and promotional effort stochastic demand. J. Control. Decis. 2019, 6, 191-215. [CrossRef]

29. Mashud, A.H.M.; Hasan, M.R.; Wee, H.M.; Daryanto, Y. Non-instantaneous deteriorating inventory model under the joined effect of trade-credit, preservation technology and advertisement policy. Kybernetes 2020, 49, 1645-1674. [CrossRef] 
30. Khan, M.A.A.; Shaikh, A.A.; Konstantaras, I.; Bhunia, A.K.; Cárdenas-Barrón, L.E. Inventory models for perishable items with advanced payment, linearly time-dependent holding cost and demand dependent on advertisement and selling price. Int. J. Prod. Econ. 2020, 230, 107804. [CrossRef]

31. San-José, L.A.; Sicilia, J.; Abdul-Jalbar, B. Optimal policy for an inventory system with demand dependent on price, time and frequency of advertisement. Comput. Oper. Res. 2021, 128, 105169. [CrossRef]

32. Cao, Y.; Duan, Y. Joint production and pricing inventory system under stochastic reference price effect. Comput. Ind. Eng. 2020, 143, 106411. [CrossRef] 